\title{
Spectrophotometric Investigation of the Interactions between Cationic (C.I. Basic Blue 9) and Anionic (C.I. Acid Blue 25) Dyes in Adsorption onto Extracted Cellulose from Posidonia oceanica
}

Douissa NB*, Dridi-Dhaouadi S and Mhenni MF

Research Unity of Applied Chemistry and Environment, Department of Chemistry, Faculty of Sciences, University of Monastir, 5019 Tunisia

\begin{abstract}
Extracted cellulose from Posidonia oceanica was used as an adsorbent for removal of a cationic (Basic blue 9 , $\mathrm{BB}$ ) and anionic textile dye (Acid blue 25, AB) from aqueous solution in single dye system. Characterization of the extracted cellulose and extracted cellulose-dye systems were performed using several techniques such as Fourier transform infrared spectroscopy (FTIR), X-ray photoelectron spectroscopy (XPS), zeta potential and Boehm acidbase titration method. Adsorption tests showed that the extracted cellulose presented higher adsorption of BB than $A B$ in single dye system, revealing that electrostatic interactions are responsible, in the first instance, for the dyeadsorbent interaction. In single dye systems, the extracted cellulose presented the maximum adsorption capacities of $B B$ and $A B$ at 0.955 and $0.370 \mathrm{mmol}^{-1} \mathrm{~g}^{-1}$, respectively.

Adsorption experiments of $A B$ dye on extracted cellulose saturated by $B B$ dye exhibited the release of the latter dye from the sorbent which lead to dye-dye interaction in aqueous solution due to electrostatic attraction between both species. Interaction of $\mathrm{BB}$ and $\mathrm{AB}$ dyes were investigated using spectrophotometric analysis and results demonstrated the formation of a molecular complex detected at wavelengths 510 and $705 \mathrm{~nm}$ when anionic $(\mathrm{AB})$ and cationic $(\mathrm{BB})$ dye were taken in equimolar proportions. The adsorption isotherm of $\mathrm{AB}$, taking into account the dye-dye interaction was investigated and showed that $B B$ dye was released proportionately by $A B$ equilibrium concentration. It was also observed that $A B$ adsorption is widely enhanced when the formation of the molecular complex is disadvantaged.
\end{abstract}

Keywords: Extracted cellulose; Single dye system; Extracted cellulose saturated by BB dye; Dye-dye interactions; Molecular complex

\section{Introduction}

Dyes are complex aromatic substances essential in many industries such as textile, paper, paint, leather and pharmaceutical. Compared with natural dyes [1], synthetic dyes are superior in terms of color availability, easiness to use, quick-setting and ensured by accurate formulas [2]. However, most of the dyes are stable to light, heat and many oxidizing agents, and more difficult to be biodegraded. With the introduction of strict environmental legislation, effluents containing dyes require proper treatment prior to discharge, not only for their high chemical oxygen demand (COD), suspended solids and toxic breakdown products, but also for color, which is not only highly visible and undesirable, but also harm the environment and cause health problems to humans and aquatic animals.

In this context, several methods of decolourization were used such as biological treatment [3], coagulation-flocculation [4] chemical and electrochemical oxidation [5-7]. However, these treatments are generally expensive and their effectiveness is sometimes asked. Sorption onto solid surface, namely adsorption, has proven to be an effective and cheaper process for removing pollutants from textile effluents due to its simplicity and high efficiency. However, the conventional solid retention, usually activated carbons [8] remains for the professionals a relatively expensive material [9]. Recent studies have been conducted to propose alternative sorbents.

Posidonia oceanica (P.oceanica), a local biomass abundant on the coasts of Tunisia has shown its effectiveness in removing organic pollutants (textile dyes [10-13]) and inorganic (heavy metals [10,11]). The cellulosic material namely cellulose and hemicellulose, presented the major constituent of the Posidonia oceanica (62\%) with a relatively high lignin (27\%) [14]. During this work, firstly, the extracted cellulose from the marine plant is used to remove cationic (Basic blue 9, BB) and anionic dye (Acid blue 25, $\mathrm{AB}$ ) from aqueous solution in single dye system. Secondly, adsorption of an anionic dye $(\mathrm{AB})$ onto extracted cellulose previously saturated by cationic dye (BB) was investigated to understand the adsorption mechanism and the dye-dye interactions on one hand and between the dyes and the adsorbent on the other hand.

\section{Experimental}

\section{Adsorbent preparation}

Posidonia oceanica's balls were collected from Tunisian coasts. They were washed with tap water to remove sand and other solids, dried in sunlight, crushed into small pieces $(45-1000 \mu \mathrm{m})$ using a grinder (AM80 Nx2), then washed repeatedly with distilled water and finally dried in an oven at $60^{\circ} \mathrm{C}$ for $24 \mathrm{~h}$. The cellulose extraction was performed using the follow protocol [15]. The powdered material $(20 \mathrm{~g})$ was first treated with $100 \mathrm{~mL}$ of a 3 mol. $\mathrm{L}^{-1}$ sodium hydroxide solution at $100^{\circ} \mathrm{C}$ for $4 \mathrm{~h}$. This alkaline treatment removes both lignin and hemicellulose. The residue was collected by filtration, washed with

*Corresponding author: Najoua Ben Douissa, Research Unity of Applied Chemistry and Environment, Department of Chemistry, Faculty of Sciences, University of Monastir, 5019 Tunisia, Tel: +21655871209; Fax: +216 73500 278; E-mail: najoua_bendouissa_2000@yahoo.fr

Received January 13, 2016; Accepted February 15, 2016; Published February 22, 2016

Citation: Douissa NB, Dridi-Dhaouadi S, Mhenni MF (2016) Spectrophotometric Investigation of the Interactions between Cationic (C.I. Basic Blue 9) and Anionic (C.I. Acid Blue 25) Dyes in Adsorption onto Extracted Cellulose from Posidonia oceanica. J Textile Sci Eng 6: 240. doi:10.4172/2165-8064.1000240

Copyright: (c) 2016 Douissa NB, et al. This is an open-access article distributed under the terms of the Creative Commons Attribution License, which permits unrestricted use, distribution, and reproduction in any medium, provided the original author and source are credited. 
Citation: Douissa NB, Dridi-Dhaouadi S, Mhenni MF (2016) Spectrophotometric Investigation of the Interactions between Cationic (C.I. Basic Blue 9) and Anionic (C.I. Acid Blue 25) Dyes in Adsorption onto Extracted Cellulose from Posidonia oceanica. J Textile Sci Eng 6: 240. doi:10.4172/2165-8064.1000240

Page 2 of 9

distilled water, and then dried in an oven for $16 \mathrm{~h}$ at $50^{\circ} \mathrm{C}$. In order to eliminate the pectin as well as some residuals lignin that gives brown colour to the biomass, conventional bleaching treatment was used. In fact, $10 \mathrm{~g}$ of the cellulose were agitated with $\mathrm{NaClO}$ solution $(100 \mathrm{~mL}$; $\mathrm{pH} 10)$ at $50^{\circ} \mathrm{C}$ for $90 \mathrm{~min}$. After filtration, the residue was washed thoroughly with distilled water until the filtrate was neutral, dried in sunlight for two days, and then stored in plastic bottles for further use.

The second adsorbent of this study is extracted cellulose from Posidonia oceanica saturated by the basic dye BB. Indeed, the cellulosic material (5 g.. $\left.\mathrm{L}^{-1}\right)$ is brought into contact with a solution of dye [BB] $=1 \mathrm{~g} . \mathrm{L}^{-1}$ in the aqueous dye solution $\mathrm{pH}$ (without addition of acid or base) ( $\mathrm{pH}=6.2 \pm 0.4)$. The whole is subjected to continuous agitation of $150 \mathrm{rpm}$ (Heidolph Vibramaxe 100) for $24 \mathrm{~h}$. The extracted cellulose is filtered and washed thoroughly with distilled water until the filtrate became clear water. Residual concentrations of $\mathrm{BB}$ in all filtrates solutions were determined using the colorimetric method at the maximum wavelength of $\mathrm{BB}$ dye $(655 \mathrm{~nm})$. Thereafter, the adsorbed amount of $\mathrm{BB}$ on extracted cellulose was calculated as $0.586 \mathrm{mmol.g}{ }^{-1}$.

\section{Characterization of materials}

Acidic sites on extracted cellulose were determined by the acidbase titration method proposed by Boehm [16]. Aqueous solutions of $\mathrm{NaHCO}_{3}\left(0.05 \mathrm{~mol} . \mathrm{L}^{-1}\right), \mathrm{Na}_{2} \mathrm{CO}_{3}\left(0.05 \mathrm{~mol} . \mathrm{L}^{-1}\right)$ and $\mathrm{NaOH}(0.05 \mathrm{~mol}$ $\left.\mathrm{L}^{-1}\right)$ were prepared. A volume $25 \mathrm{~mL}$ of these solutions was added to $0.5 \mathrm{~g}$ of extracted cellulose, shaking for $48 \mathrm{~h}$ and then centrifuged. The excess of base was then determined by back titration using $\mathrm{NaOH}$ $\left(0.05 \mathrm{~mol} \mathrm{~L}^{-1}\right)$ and $\mathrm{HCl}\left(0.025 \mathrm{~mol} . \mathrm{L}^{-1}\right)$. All titrations were carried out at room temperature. The number of acidic sites was determined under the assumptions that $\mathrm{NaOH}$ neutralizes carboxylic, lactonic, and phenolic groups; that $\mathrm{Na}_{2} \mathrm{CO}_{3}$ neutralizes carboxylic and lactonic groups; and that $\mathrm{NaHCO}_{3}$ neutralizes only carboxylic groups. The test was repeated at least three times.

The Zeta potential of extracted cellulose was measured with Zeta Meter System 3.0. $100 \mathrm{mg}$ of extracted cellulose were added to $100 \mathrm{~mL}$ of distilled water. After $\mathrm{pH}$ adjustment, mixing for $2 \mathrm{~h}$ and centrifugation of the sorbent suspension, the filtrate was placed in the electrophoresis cell for zeta potential measurements. The measurements were repeated at least five times.

Scanning electron microscopy (SEM) analysis was carried out on the extracted cellulose to study its surface texture. The micrograph was recorded on a ZEISS-ULTRA55 SEM device, operating at $10 \mathrm{kV}$. Prior to the analysis by SEM, the surface was coated with a gold/palladium layer.

Several methods were used to characterize the extracted cellulose, before and after dye adsorption. The FT-IR spectra were recorded in a bio-Rad spectrophotometer. The analysis was applied on different samples to determine the surface functional groups. The acquisition conditions were 64 scans and $4 \mathrm{~cm}^{-1}$ resolution. The wavenumber scanning was in the range of $500-4000 \mathrm{~cm}^{-1}$.

The X-ray photoelectron spectroscopy (XPS) experiments were performed with a XR3E2 apparatus (Vacuum Generators, UK) equipped with a monochromated $\mathrm{MgKa} \mathrm{X}$-ray source $(1253.6 \mathrm{eV})$ and operating at $15 \mathrm{kV}$ under a current of $20 \mathrm{~mA}$. Samples were placed in an ultrahigh vacuum chamber $\left(10^{-8} \mathrm{mbar}\right)$ with electron collection by a hemispherical analyzer at an angle of $90^{\circ}$. The signal decomposition was realised using Spectrum NT, and the CAH signal was used as a reference peak at $285.0 \mathrm{eV}$. XPS analysis was performed in extracted cellulose before and after dye adsorption.

\section{Dyes and analysis}

$\mathrm{AB}$ (molecular formula $=\mathrm{C}_{20} \mathrm{H}_{14} \mathrm{~N}_{2} \mathrm{O}_{5} \mathrm{~S}, \lambda_{\max }=602 \mathrm{~nm}$ ) and $\mathrm{BB}$ (molecular formula $=\mathrm{C}_{16} \mathrm{H}_{18} \mathrm{~N}_{3} \mathrm{SCl}, \lambda_{\max }=655 \mathrm{~nm}$ ) were supplied by Reactifs-RAL and used without further purification. The characteristics and structure of these dyes is presented in Figure 1. The test solutions were prepared by diluting stock solutions to the desired concentrations. The UV-vis spectra of aqueous dye solutions were measured by a double beam UV/vis spectrophotometer (Cecil instrument, Model CE2021-2000).

\section{Batch sorption studies}

A fixed amount of extracted cellulose $(0.25 \mathrm{~g})$ was added to a set of bottles (Teflon) containing $50 \mathrm{~mL}$ of known concentration of $\mathrm{AB}$ and $\mathrm{BB}$ dyes in single solution at $\mathrm{pH}$ around 6.2 (without addition of acid or base). The bottles were agitated at $150 \mathrm{rpm}$ (Heidolph Vibramaxe 100 shaker) and at temperature of $21^{\circ} \mathrm{C}$ until equilibrium was reached. Then, samples were centrifuged at $2000 \mathrm{rpm}$ for $2 \mathrm{~min}$, and the supernatant was analyzed for the residual $\mathrm{AB}$ and $\mathrm{BB}$ concentration (by measuring the absorbance at 602 and $665 \mathrm{~nm}$ for $\mathrm{AB}$ and $\mathrm{BB}$, respectively) using a double beam UV/VIS spectrophotometer (Cecil instrument, Model CE2021-2000).

On the other hand, bottles' series of $\mathrm{AB}$ solutions $(50 \mathrm{~mL})$ at different initial concentrations $\left(0-1\right.$ g. $\left.\mathrm{L}^{-1}\right)$ were placed in contact with $0.25 \mathrm{~g}$ of extracted cellulose saturated by the basic dye BB. The flasks were agitated at $150 \mathrm{rpm}$ (at temperature of $21^{\circ} \mathrm{C}$ ) until equilibrium was reached and centrifuged at $2000 \mathrm{rpm}$ for $2 \mathrm{~min}$. The residual dye solutions after adsorption were scanned over the whole visible range. In this work, the classical equations Freundlich and Langmuir were used to model experimental curves and the equilibrium models were fitted employing the non-linear fitting method, using the non-linear fitting facilities of the software Microcal Origin 6.0.

\section{Results and Discussion}

\section{Characterization of extracted cellulose}

Figure 2 shows the SEM micrograph of the extracted cellulose sample. The extracted cellulose has considerable numbers of heterogeneous layers and pores which may be very interesting for dye adsorption.

Table 1 summarizes the results of Boehm titration of extracted cellulose and shows that most of acidic functional groups are carboxylic, followed by phenolic and then lactonic.

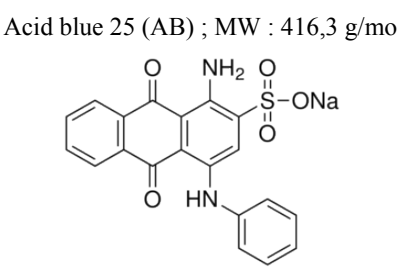

Basic blue 9 (BB) ; MW : 319,85 g/mol

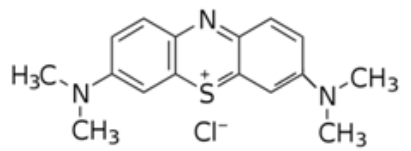

Figure 1: Pore size volume defining device of specimens. 
Citation: Douissa NB, Dridi-Dhaouadi S, Mhenni MF (2016) Spectrophotometric Investigation of the Interactions between Cationic (C.I. Basic Blue 9) and Anionic (C.I. Acid Blue 25) Dyes in Adsorption onto Extracted Cellulose from Posidonia oceanica. J Textile Sci Eng 6: 240. doi:10.4172/2165-8064.1000240

Page 3 of 9

The wide survey scan spectra are shown in Figure 3. The spectrum of extracted cellulose shows two strong symbol peaks for C1s and $\mathrm{O} 1 \mathrm{~s}$ at 285 and $531 \mathrm{eV}$ respectively. Three quite weak ones for $\mathrm{N} 1 \mathrm{~s}$, $\mathrm{Ca} 2 \mathrm{p} 3 / 2$ and $\mathrm{Cl} 2 \mathrm{p} 3 / 2$ can be observed at, 395.7, 345.7 and $200 \mathrm{eV}$, respectively [17]. Those observations suggest the presence of abundant $\mathrm{C}, \mathrm{O}$ and minor $\mathrm{N}, \mathrm{Ca}$ and $\mathrm{Cl}$ on the surface of the extracted cellulose. The elemental surface composition of extracted cellulose obtained by XPS is given in Table 2, which shows that the surface of the extracted fiber did not consist of pure cellulose. The O/C ratio was much lower than in pure cellulose ( 0.83 in theory). Some nitrogen, calcium and chlorine were observed, which should not be present in pure cellulose. The calcium atom has been often detected on natural celluloses [18] and the chlorine atom could be present from bleaching operation. Those results confirm that the extracted cellulose yet contains lignin and hemicelluloses.

The FT-IR spectrum of extracted cellulose shows a strong absorption band at $3430 \mathrm{~cm}^{-1}$ due to stretching of $\mathrm{O}-\mathrm{H}$ groups and
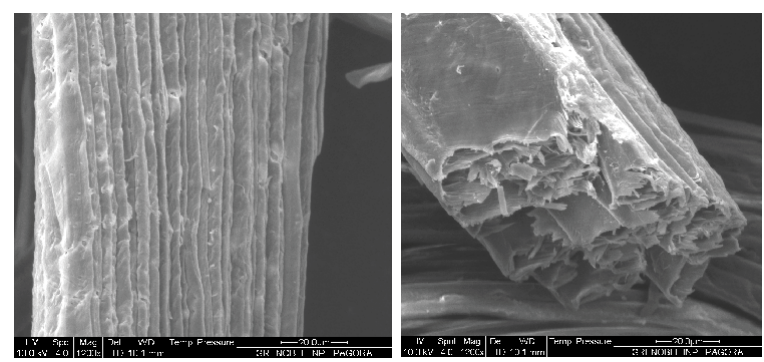

Figure 2: Scanning electron microscope image of extracted cellulose.

\begin{tabular}{|c|c|c|c|c|}
\hline $\mathbf{p H}_{\mathrm{PzC}}$ & \multicolumn{4}{|c|}{ Acidic groups $\left(\mathbf{m m o l} . \mathbf{g}^{-1}\right)$} \\
\hline & Carboxylic & Lactonic & phenolic & total \\
\hline 3.5 & 0.875 & 0.015 & 0.275 & 1.165 \\
\hline
\end{tabular}

Table 1: $\mathrm{pH}_{\mathrm{PZC}}$ value and Boehm titration results of extracted cellulose.

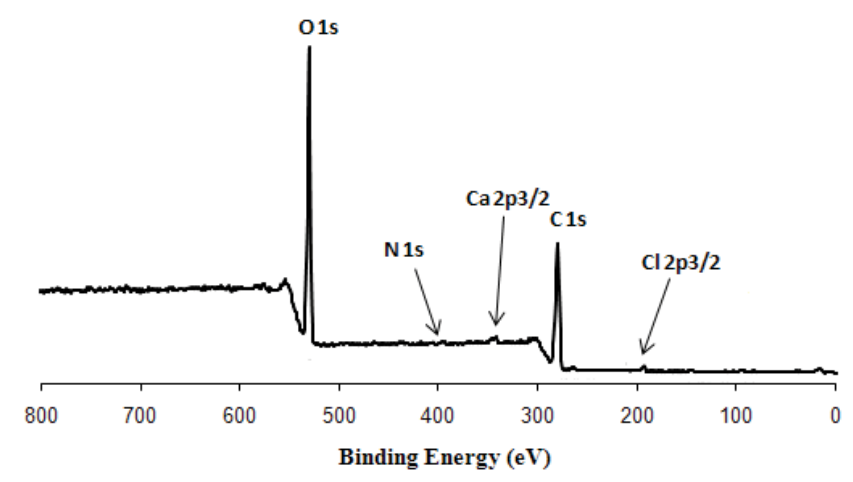

Figure 3: XPS wide survey scans spectra of the extracted cellulose.

\begin{tabular}{|l|c|c|c|c|c|c|c|c|}
\hline & \multicolumn{9}{|c|}{ Surface composition (at percentage) } & & \\
\hline & $\mathrm{O}$ & $\mathrm{C}$ & $\mathrm{N}$ & $\mathrm{Ca}$ & $\mathrm{Cl}$ & $\mathrm{S}$ & $\mathrm{O} / \mathrm{C}$ & $\mathrm{S} / \mathrm{C}$ \\
\hline Extracted cellulose & 35.62 & 61.78 & 0.68 & 0.41 & 0.67 & - & 0.57 & - \\
\hline $\begin{array}{l}\text { Extracted cellulose } \\
\text { after AB adsorption }\end{array}$ & 36.17 & 62.90 & 0.91 & 0.09 & 0.13 & 0.04 & - & $6,3.10^{-4}$ \\
\hline $\begin{array}{l}\text { Extracted cellulose } \\
\text { after BB adsorption }\end{array}$ & 28.20 & 67.93 & 2.33 & 0.17 & 0.71 & 0.08 & 0.42 & - \\
\hline
\end{tabular}

Table 2: The elemental surface composition from XPS wide survey spectra. that one at $2891 \mathrm{~cm}^{-1}$ to the $\mathrm{C}-\mathrm{H}$ stretching. The band at $1651 \mathrm{~cm}^{-1}$ corresponds to the bending mode of the absorbed water [19] but can also be assigned to the absorption of carboxylic groups.

\section{Dye adsorption in single-dye solutions}

Effect of the solution $\mathrm{pH}$ on dye adsorption: The influence of equilibrium $\mathrm{pH}$ on the $\mathrm{BB}$ and $\mathrm{AB}$ sorption was investigated between 3 and 11 and the results are shown in Figure 4. Dyes sorption onto extracted cellulose appeared to be strongly $\mathrm{pH}$-dependent. Increasing the $\mathrm{pH}$ value from 3 to 4 resulted in a considerable increase in $\mathrm{BB}$ sorption and higher decrease in $\mathrm{AB}$ one, whereas further increasing the $\mathrm{pH}$ value from 4 to 10 yielded a slight change in sorption, and this for both dyes. This tendency correlated well with the variation of surface charge of the extracted cellulose (the $\mathrm{pH}$ of point zero charge $\mathrm{pH}_{\mathrm{ZPC}}$ measured by electrophoresis is 3.5). Consequently, for $\mathrm{pH}$ values lower than $\mathrm{pH}_{\mathrm{PZC}}$ the sorbent exhibits a positive surface charge. The higher amount of anionic dye $(\mathrm{AB})$ sorbed at $\mathrm{pH}$ values lower than 3.5 can be explained by the electrostatic interactions between the positively charged surface of the sorbents and of the negatively charged $A B$ dye. For $\mathrm{pH}$ higher than 3.5 the extracted cellulose surface is negatively charged. This further indicates that cationic dye (BB) sorption was also driven primarily via electrostatic interaction.

Equilibrium sorption isotherms: The sorption studies of $A B$ and $\mathrm{BB}$ dyes in single dye solutions onto extracted cellulose were carried out in a batch reactor by varying the initial concentrations of the studied dyes at an initial $\mathrm{pH}$ of $6.2 \pm 0.4$. Nonlinear regression was used to fit the dye sorption isotherm to the Freundlich and the Langmuir (Table 3 ). Based on the $R^{2}$ values the best isotherm model fitted for extracted cellulose sorbents is the Langmuir model (Figure 5). Adsorption capacities of $\mathrm{BB}$ and $\mathrm{AB}$ on the extracted cellulose were determined to be 0.955 and $0.370 \mathrm{mmol} / \mathrm{g}$, respectively. The successful application of this model to the present data supports that all adsorption sites are energetically and sterically independent of the adsorbed amount [20]. The solid is assumed to have a limited adsorption capacity, which defines sorbent's total capacity.

\section{Dye-cellulose interaction characterization}

FTIR study: In order to illustrate interaction between, firstly BB and extracted cellulose and secondly $\mathrm{AB}$ and extracted cellulose, to suggest responsible sites for adsorption, analysis FTIR of this sorbent after adsorption were investigated. Figure 6 shows the FTIR spectra of $\mathrm{BB}, \mathrm{AB}$ and extracted cellulose before and after dye adsorption. Figure 6a shows the extracted cellulose spectra. For BB (Figure 6b), stretching vibration of tertiary amine groups is observed at $3422 \mathrm{~cm}^{-1}$. Bands corresponding to the C-H stretching vibration are at 2919 and $2849 \mathrm{~cm}^{-1}$. The stretching vibration of nitrile groups is at $2700 \mathrm{~cm}^{-1}$. Vibrations of the aromatic ring are found at 1597 and $1538 \mathrm{~cm}^{-1}$. The $\mathrm{C}-\mathrm{N}$ stretching vibration is at $1337 \mathrm{~cm}^{-1}$. The $\mathrm{C}-\mathrm{H}$ 'in plane' vibrations are found between 1253 and $1037 \mathrm{~cm}^{-1}$ and 'out of plane' vibration is at $945 \mathrm{~cm}^{-1}$ [21].

Similarly, for $A B$ Figure $6 c$ reveals the presence of several peaks of AB's characteristic functional groups. The stretching vibrations observed at 3410 and $1185 \mathrm{~cm}^{-1}$ mark the presence of amine groups, band corresponding to the $\mathrm{CH}$ stretching vibration is at $2920 \mathrm{~cm}^{-1}$, the functional groups of the aromatic ring such as $\mathrm{C}=\mathrm{C}$ and $\mathrm{C}=\mathrm{O}$ are located at around $1560 \mathrm{~cm}^{-1}$, the $\mathrm{CN}$ stretching vibration is at 1360 $\mathrm{cm}^{-1}, \mathrm{CH}$ vibration is at $1262 \mathrm{~cm}^{-1}$ and the band at $1017 \mathrm{~cm}^{-1}$ can be assigned to the $\mathrm{S}=\mathrm{O}$ bond according to Auta and Hameed [22].

It is noted that the shoulder observed between 1100 and 1000 
Citation: Douissa NB, Dridi-Dhaouadi S, Mhenni MF (2016) Spectrophotometric Investigation of the Interactions between Cationic (C.I. Basic Blue 9) and Anionic (C.I. Acid Blue 25) Dyes in Adsorption onto Extracted Cellulose from Posidonia oceanica. J Textile Sci Eng 6: 240. doi:10.4172/2165-8064.1000240

$\mathrm{cm}^{-1}$ in cellulose spectrum, which corresponds to the deformation vibrations in the plane of hydroxyl groups of alcohols, is modified after incorporation of the dyes. The peaks that appear in (d) and (e) to 1341 $\mathrm{cm}^{-1}$ correspond to the $\mathrm{CN}$ stretching vibration at each dye (Figures $6 \mathrm{~b}$ and $6 \mathrm{c}$ ). In addition, after adsorption of $\mathrm{AB}$ (Figure $6 \mathrm{~d}$ ) the band at $1020 \mathrm{~cm}^{-1}$, which corresponds in the case of raw material (a) to the CO stretching vibration has changed appearance at the cellulose adsorbed $\mathrm{AB}(\mathrm{d})$ marking the presence of $\mathrm{S}=\mathrm{O}$ bond at $1017 \mathrm{~cm}^{-1}$. Two other peaks appear at the shoulder at 1128 and $1080 \mathrm{~cm}^{-1}$ which probably correspond to the involvement of the carbon group C2 and C6 of the representative unit of the cellulose after dyes adsorption.

Besides peaks' shift positions, the intensity and sharpness of the bands observed for the raw material were also affected after dyes adsorption. The broadband at $3420 \mathrm{~cm}^{-1}$ of extracted cellulose (Figure 6a) becomes slightly narrow after dyes adsorption (Figures $6 \mathrm{~d}$ and $6 \mathrm{e}$ ), indicating the possibility of the involvement of hydroxyl groups of the extracted cellulose in the adsorption process.

Thus, it can be concluded that the $\mathrm{OH}$ group of the material interacts with the nitrogen atom on the $\mathrm{BB}$ or $\mathrm{AB}$ with hydrogen

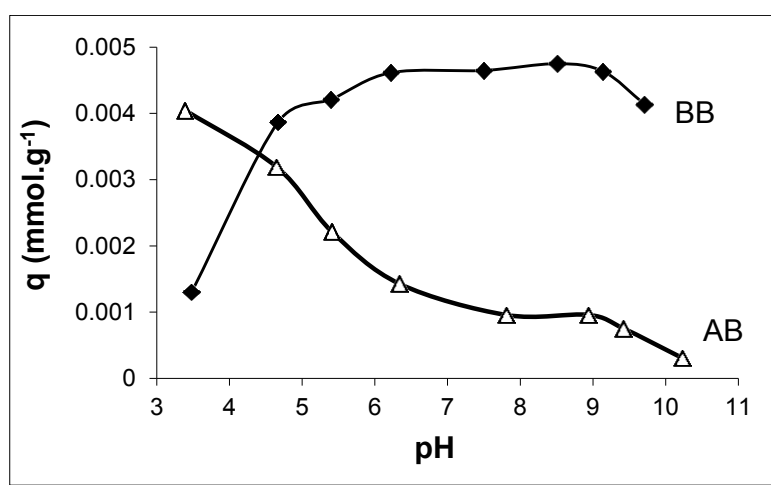

Figure 4: Effect of $\mathrm{pH}$ on $\mathrm{AB}$ and $\mathrm{BB}$ adsorption onto extracted cellulose (initial dye concentration: $10 \mathrm{mg} \cdot \mathrm{L}^{-1}$, temperature: $22^{\circ} \mathrm{C}$ )

\begin{tabular}{|c|c|c|c|c|c|c|}
\hline Dye & \multicolumn{3}{|c|}{ Langmuir } & \multicolumn{3}{c|}{ Freundlich } \\
\hline & $\begin{array}{c}\mathbf{q}_{m} \\
\left(\mathbf{m m o l . g}^{-1}\right)\end{array}$ & $\begin{array}{c}\mathbf{K}_{\mathrm{L}} \\
\left(\mathbf{L} \mathbf{~ m m o l}^{-1}\right)\end{array}$ & $\mathbf{R}^{\mathbf{2}}$ & $\begin{array}{c}\mathbf{K}_{\mathbf{F}} \\
\left(\mathbf{m m o l}^{n-1 / n} \mathbf{L}^{1 / n} \mathbf{g}^{-1}\right)\end{array}$ & $\mathbf{n}$ & $\mathbf{R}^{\mathbf{2}}$ \\
\hline BB & 0.955 & 11.64 & $\mathbf{0 . 9 9}$ & 2.22 & 1.56 & 0.98 \\
\hline AB & 0.370 & 0.95 & $\mathbf{0 . 9 5}$ & 0.17 & 1.49 & 0.91 \\
\hline
\end{tabular}

Table 3. Isotherm parameters for $A B$ and $B B$ sorption on extracted cellulose. bonding [21]. Since the $\mathrm{N}$ atom in $\mathrm{BB}$ is linked to the aromatic rings or to the terminal methyl groups, or in $\mathrm{AB}$ is linked to the primary or secondary amine, the vibrational frequencies of the aromatic ring and other groups will be affected when nitrogen is involved in a hydrogen bonding interaction.

$\mathrm{X}$-ray photoelectron analysis (XPS): After dyes adsorption atomic composition of the surface varied considerably. After BB sorption, increasing of $\mathrm{C}, \mathrm{N}$ and $\mathrm{Cl}$ amounts and decreasing $\mathrm{O}$ and $\mathrm{Ca}$ one (Table 2), and the appearance of $\mathrm{S} 2 \mathrm{p} 3 / 2$ at $164 \mathrm{eV}$ binding energy was observed. The increase in $\mathrm{C}, \mathrm{S}, \mathrm{N}$ and $\mathrm{Cl}$ atomic composition come from the presence of $\mathrm{BB}$ species at the surface. While, increasing of $\mathrm{C}, \mathrm{O}$ and $\mathrm{N}$ amounts and decreasing $\mathrm{Cl}$ and $\mathrm{Ca}$ one (Table 2), and the appearance of $\mathrm{S}$ was observed after $\mathrm{AB}$ adsorption.

It can be seen from $\mathrm{BB}$ molecule formula, that this latter present no oxygen atom, thus, it was interesting to compare $\mathrm{O} / \mathrm{C}$ ratio of extracted cellulose and the resulting material after adsorption (Table 2). Reciprocally, $S / C$ ratio of $A B$ and extracted cellulose adsorbed the anionic dye was compared. From these values, it is easy to calculate the adsorption capacity of each dye and it could be measured as 2.05 and 0.34 mmol.g $\mathrm{g}^{-1}$ for $\mathrm{BB}$ and $\mathrm{AB}$, respectively. The adsorption capacity (from adsorption isotherm study) of samples analyzed with XPS was measured as 0.955 and $0.0465 \mathrm{mmol}^{-1} \mathrm{~g}^{-1}$ for $\mathrm{BB}$ and $\mathrm{AB}$, respectively, which is lower than the calculated one from XPS results. The AB and $\mathrm{BB}$ species might exit preferentially at the surface of the fiber rather than in its porosity.

\section{$A B$ adsorption on extracted cellulose loaded with MB dye}

Highlighting dye-dye interactions: The visible absorption spectra of $\mathrm{AB}$ and $\mathrm{BB}$ were used for the analysis of dyes in single dye solutions. The single solutions of $\mathrm{AB}$ and $\mathrm{BB}$ containing 20 and $10 \mathrm{mg}$ $\mathrm{L}^{-1}$, respectively of dyes were prepared and the visible spectra of these solutions were recorded between 400 and $800 \mathrm{~nm}$ (Figure 7). As it can be seen from Figure 7 , maximum wavelength $\left(\lambda_{\text {mon }}\right)$ of $\mathrm{AB}$ and $\mathrm{BB}$ were determined as $602 \mathrm{~nm}$ and $665 \mathrm{~nm}$, respectively. The calibration curves were prepared at $\lambda_{\max }$ of each dye. On the other hand, this figure shows the addition of absorbance spectra of single solutions of $\mathrm{AB}$ and $\mathrm{BB}$ (superposition spectra) which is not in agreement with the absorbance spectra of binary solution made by $20 \mathrm{mg} \mathrm{L}^{-1}$ of $\mathrm{AB}$ and $10 \mathrm{mg} \mathrm{L}^{-1}$ of BB. This shows that the Beer-Lambert rule is not applicable due to possible interaction of dyes. So that, derivative spectrophotometry method [23], which is based on the analysis of derivative spectra, cannot therefore be applied in this case to determine the composition of a binary mixture of dyes. A series of binary solutions was prepared to cover the wide
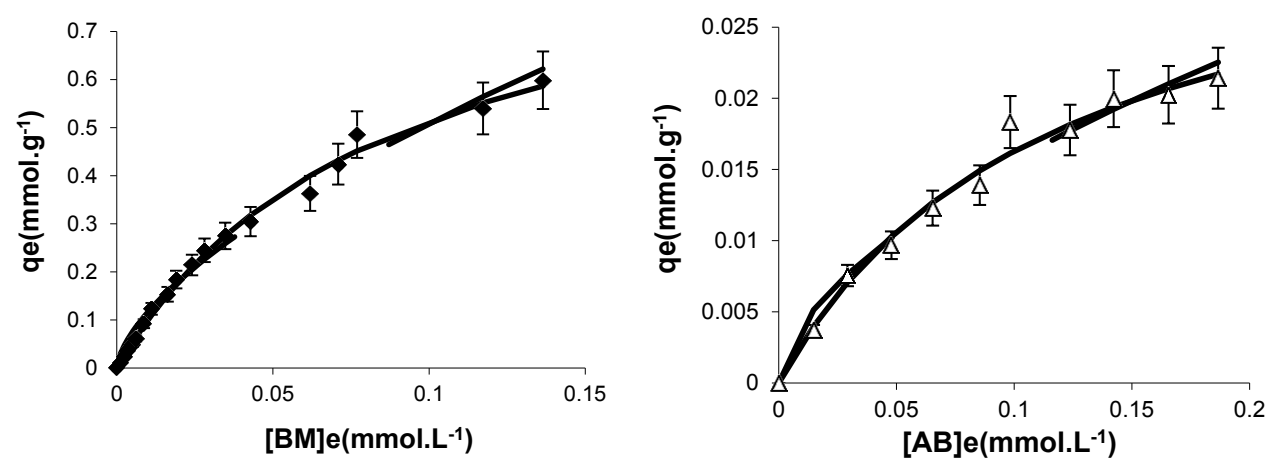

Figure 5: Non-linear sorption isotherms of $A B$ and $B B$ in single dye solution (solid lines indicate the Langmuir isotherm and dashed one the Freundlich isotherm). 
Citation: Douissa NB, Dridi-Dhaouadi S, Mhenni MF (2016) Spectrophotometric Investigation of the Interactions between Cationic (C.I. Basic Blue 9) and Anionic (C.I. Acid Blue 25) Dyes in Adsorption onto Extracted Cellulose from Posidonia oceanica. J Textile Sci Eng 6: 240. doi:10.4172/2165-8064.1000240

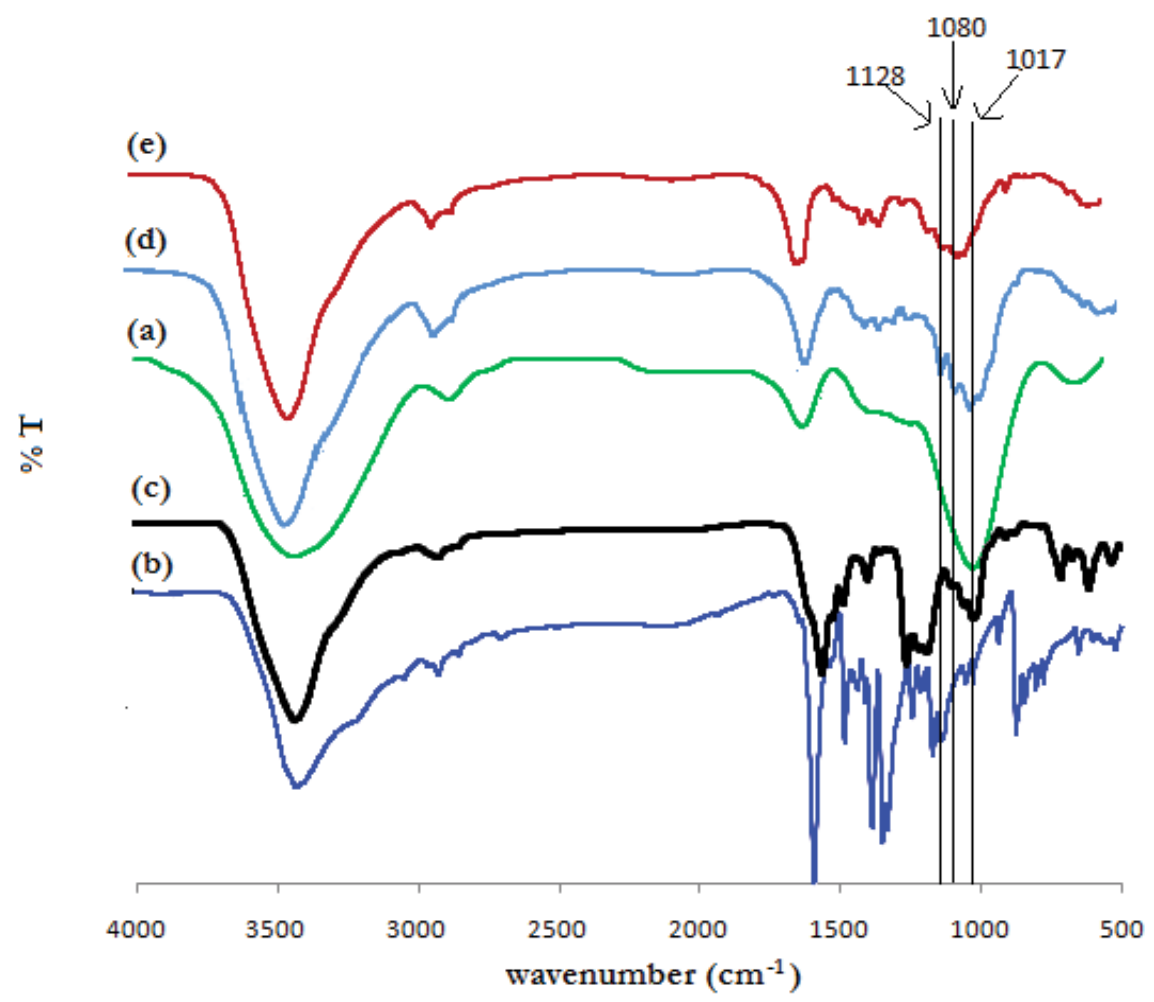

Figure 6: FT-IR spectra of (a) extracted cellulose, (b) BB, (c) AB, (d) extracted cellulose after AB adsorption and (e) extracted cellulose after BB adsorption.



BB (10mg.t-1)

$-\mathrm{AB}\left(20 \mathrm{mg} \cdot \mathrm{L}^{-1}\right)$

$B B\left(10 \mathrm{mg} \cdot \mathrm{L}^{-1}\right)+\mathrm{AB}\left(20 \mathrm{mg} \cdot \mathrm{L}^{-1}\right)$

Superposition

Figure 7: Visible absorption spectra of $A B$ and $B B$ in single and binary solutions.

range of concentrations which will allow, for identification of spectra as fingerprints to determine the composition of the mixtures in residual solutions after dye adsorption. Figures 8-10 show the spectra obtained for a wide range of binary composition mixtures.

The data spectra allow for some findings:
- If $[\mathrm{AB}]<[\mathrm{BB}]$ the mixture spectrum has a similar shape to that of $\mathrm{BB}$ spectrum (Figure 8). It is thus found that for a constant concentration of $\mathrm{BM}$ (eg. $[\mathrm{BB}]=0.626 \mathrm{mmol} \cdot \mathrm{L}^{-1}$ ), the absorbance at $665 \mathrm{~nm}$ decreases as $\mathrm{AB}$ concentration increases (provided that $[\mathrm{AB}]$ remains below $[\mathrm{BB}]$ ) and the shape of the spectrum is closer to that of $B M$ spectrum. 
Citation: Douissa NB, Dridi-Dhaouadi S, Mhenni MF (2016) Spectrophotometric Investigation of the Interactions between Cationic (C.I. Basic Blue 9) and Anionic (C.I. Acid Blue 25) Dyes in Adsorption onto Extracted Cellulose from Posidonia oceanica. J Textile Sci Eng 6: 240. doi:10.4172/2165-8064.1000240

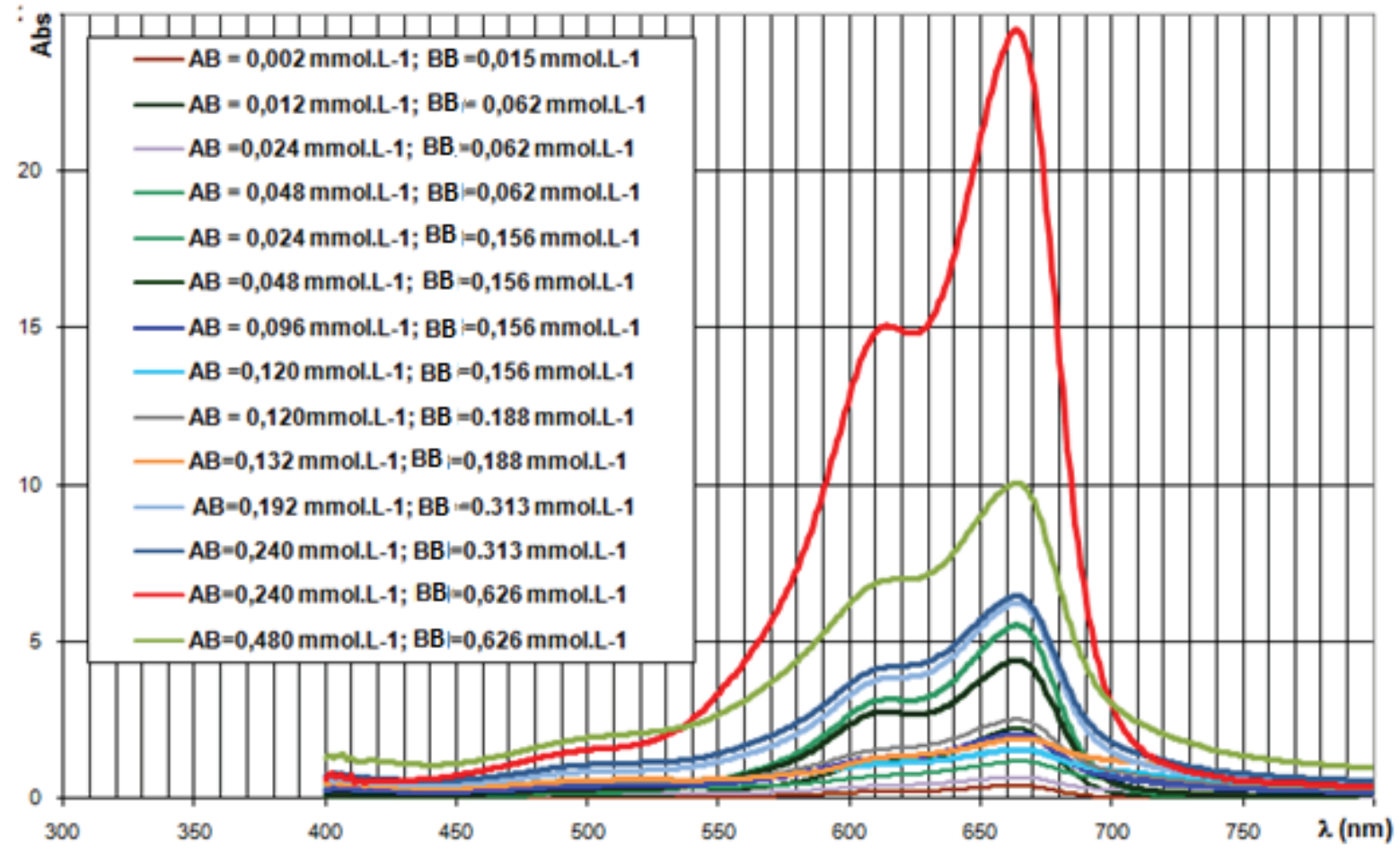

Figure 8: Spectral scanning binary mixtures for which $[A B]<[B B]$.

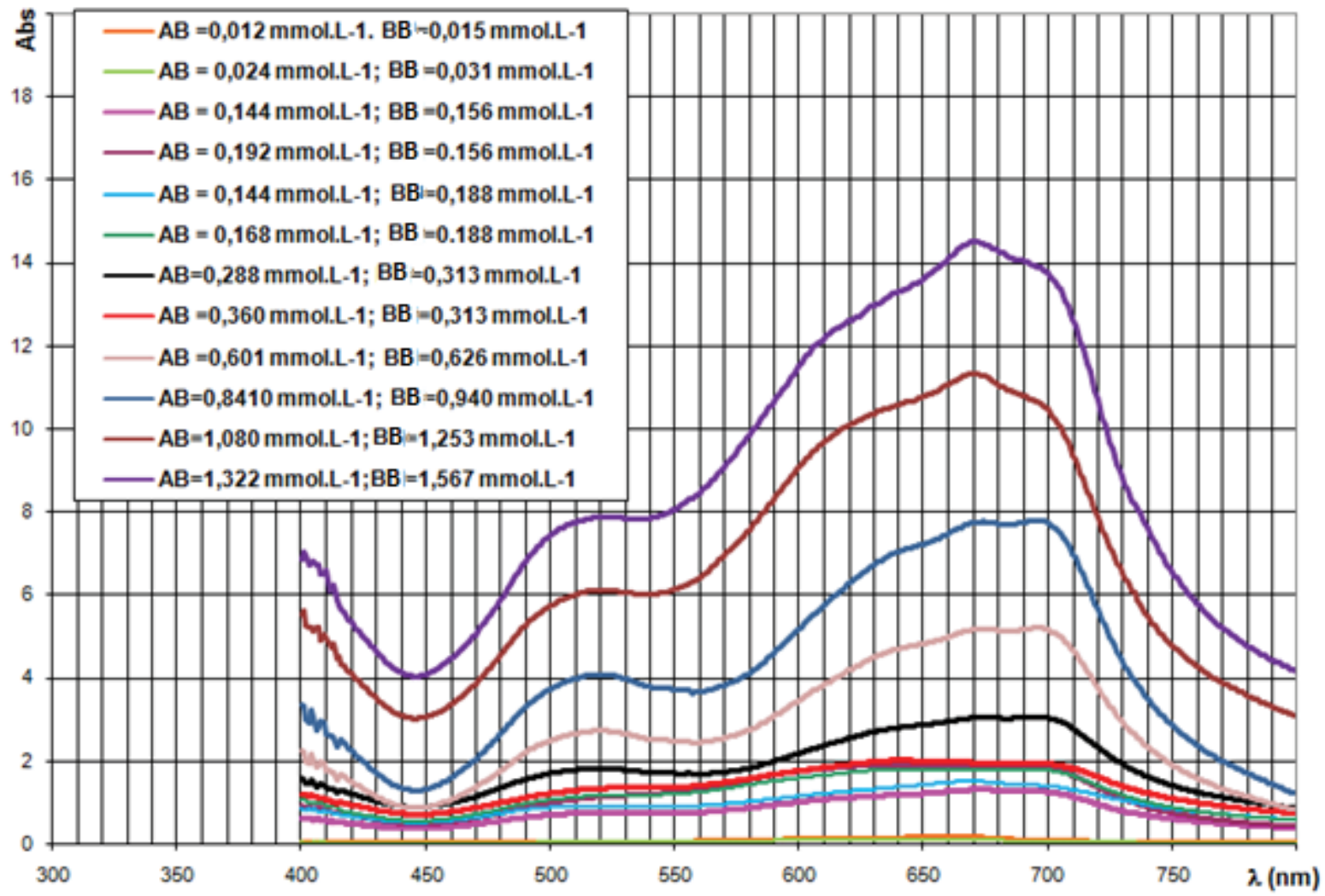

Figure 9: Spectral scanning binary mixtures for which $[A B]=[B B]$. 
Citation: Douissa NB, Dridi-Dhaouadi S, Mhenni MF (2016) Spectrophotometric Investigation of the Interactions between Cationic (C.I. Basic Blue 9) and Anionic (C.I. Acid Blue 25) Dyes in Adsorption onto Extracted Cellulose from Posidonia oceanica. J Textile Sci Eng 6: 240. doi:10.4172/2165-8064.1000240

Page 7 of 9

- If $[\mathrm{AB}]>[\mathrm{BB}]$ the mixture spectrum has rather the shape of $\mathrm{AB}$ spectrum (Figure 10).

- $\quad$ If $[\mathrm{AB}] \approx[\mathrm{BB}]$ the mixture spectrum has a third different shape from that of the two dyes, with the appearance of shoulders at 705 and $510 \mathrm{~nm}$ in addition to the maximum peak wavelength of the two dyes (Figure 9). It should be noted that in this case the absorbance of the shoulder at $705 \mathrm{~nm}$ is proportional to both concentration of $\mathrm{BB}$ and $\mathrm{AB}$. This suggests an intermediate form takes place when both dyes are present in equimolar amounts. This form, which may be a molecular complex, is detected at 705 and at $510 \mathrm{~nm}$.
Adsorption study: In this study, adsorption of the anionic dye (AB) was carried out after prior adsorption of the cationic dye (BB). The aim is to change the charge state of the adsorbent surface by the binding of the cationic dye and thus enable better sorption of anionic dye. The equilibrium adsorption of $\mathrm{AB}$ on the raw extracted cellulose and previously saturated one by BB dye was presented in Figure 11. On the practical side, the amounts of adsorbed $\mathrm{AB}$ dye in the adsorption isotherm study onto extracted cellulose saturated by $\mathrm{BB}$ dye $(\mathbf{O})$ were determined following a direct reading of the absorbance at $602 \mathrm{~nm}$ ( $\lambda_{\max }$ of $\mathrm{AB}$ ) of residual solutions without taking account of the $\mathrm{BB}$ interference. Compared to adsorption isotherm of $\mathrm{AB}$ obtained on the

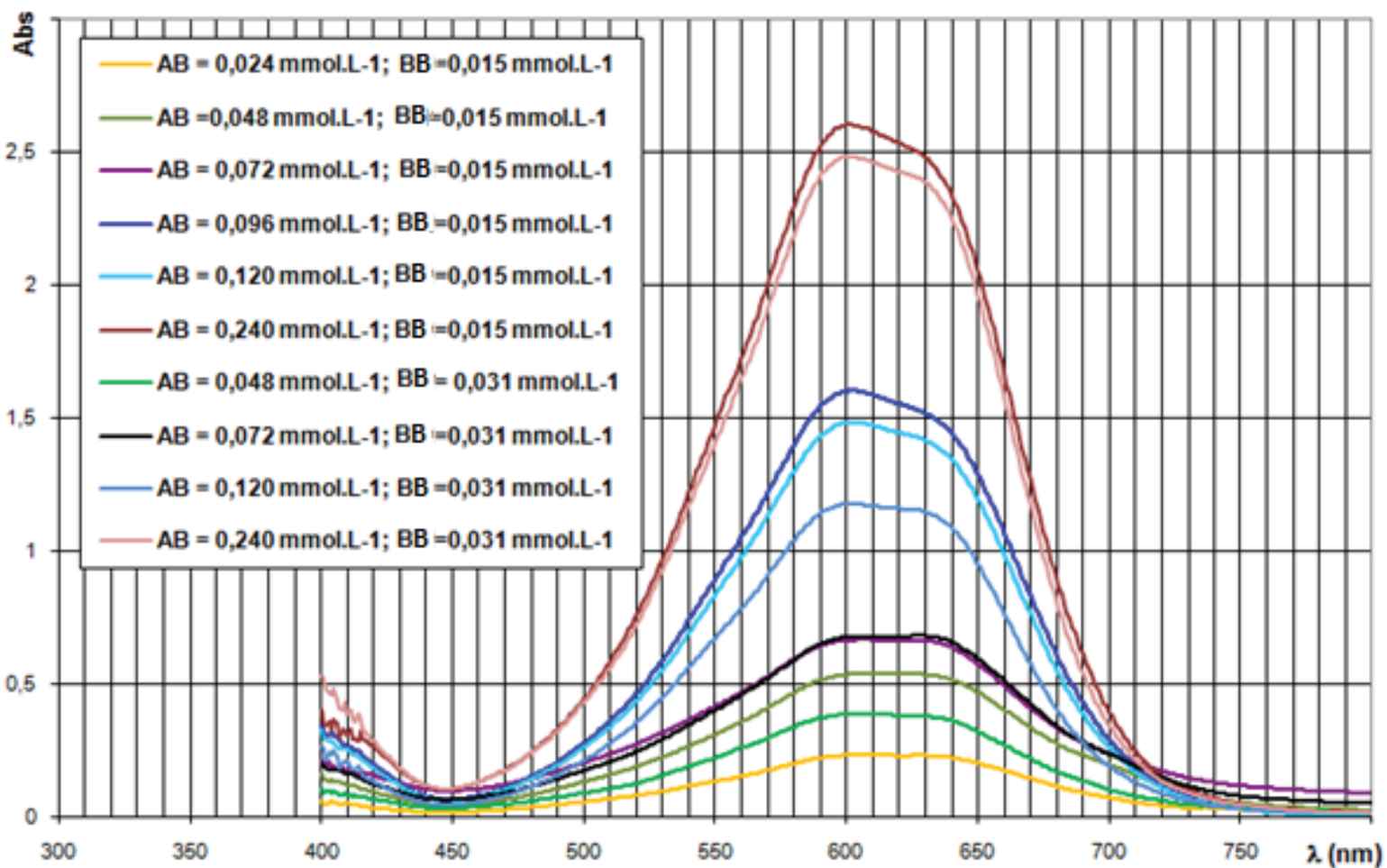

Figure 10: Spectral scanning binary mixtures for which $[A B] \square[B B]$

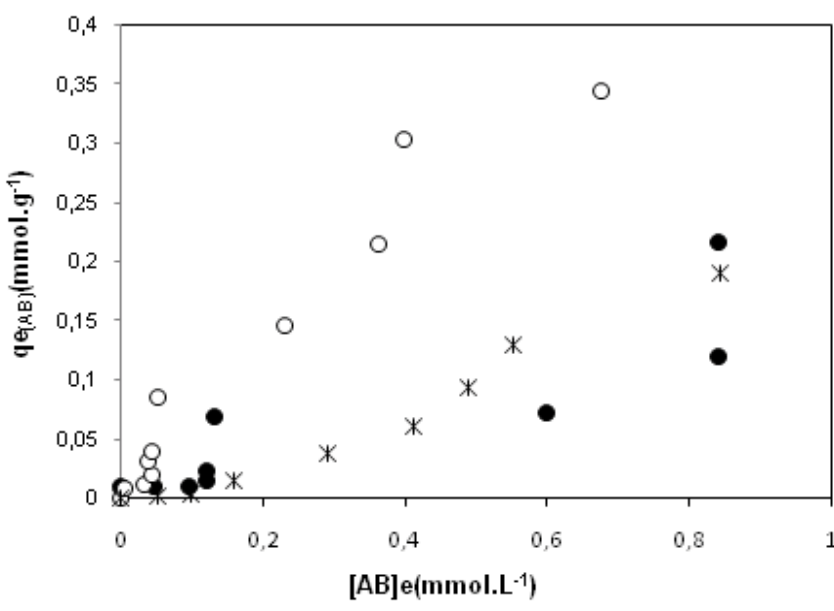

- Saturated extr. cellulose (taking account of interference)

O Saturated extr. cellulose (without taking account of interference)

* Extracted cellulose

Figure 11: Comparison of adsorption isotherms of $A B$. 
Citation: Douissa NB, Dridi-Dhaouadi S, Mhenni MF (2016) Spectrophotometric Investigation of the Interactions between Cationic (C.I. Basic Blue 9) and Anionic (C.I. Acid Blue 25) Dyes in Adsorption onto Extracted Cellulose from Posidonia oceanica. J Textile Sci Eng 6: 240. doi:10.4172/2165-8064.1000240

Page 8 of 9

raw extracted cellulose (Ж), it is noted that the quantities of adsorbed $\mathrm{AB}$ onto extracted cellulose previously saturated with $\mathrm{BB}$ dye increased significantly. Thus, we can easily conclude that cationic dye (BB) helped to modify the surface state of the extracted cellulose by increasing the number of active sites for the anionic dye and thereby improving the adsorption. However, Figures 8-10 have demonstrated the effect of the presence of a dye on the spectrophotometric analysis of the other dye. Besides the probable $\mathrm{BB}$ release in the adsorption case of $\mathrm{AB}$ affects the analysis of the latter and will be the cause of wrong results interpretation. So that, the residual dyes solutions after adsorption were scanned over the entire visible range and the results are shown through Figure 12. The recorded spectra exhibit an absorption maximum at 665 $\mathrm{nm}$ and a shoulder at $610 \mathrm{~nm}$ (Figure 12a). The shape of these spectra corresponds to $\mathrm{BB}$ one, which proves the presence of the latter which is released during $\mathrm{AB}$ adsorption.
Moreover, Figure $12 \mathrm{~b}$ shows that greater the initial $\mathrm{AB}$ concentration increases (which corresponds to the increase of the residual concentration) more the shape of the spectra is transformed with the appearance of a shoulder at $520 \mathrm{~nm}$ which appears on the dye mixture spectra (Figure 7). Thus, the identification of the solutions composition after adsorption was carried out by superposing the spectra obtained after adsorption (Figure 12) to those presented through Figures 8-10 and which correspond to the solutions at known composition. Consequently, it will be possible to determine $\mathrm{AB}$ adsorbed capacity and draw again the adsorption isotherm of the $\mathrm{AB}$ dye by taking into account the interfering presence of BB dye (Figure 11(•))

Thus, Figure 11 highlights the error made by a direct reading of the $\mathrm{AB}$ absorbance neglecting the presence of $\mathrm{BB}$ and shows that adsorption was overstated. Indeed, comparison of $\mathrm{AB}$ isotherms onto raw extracted

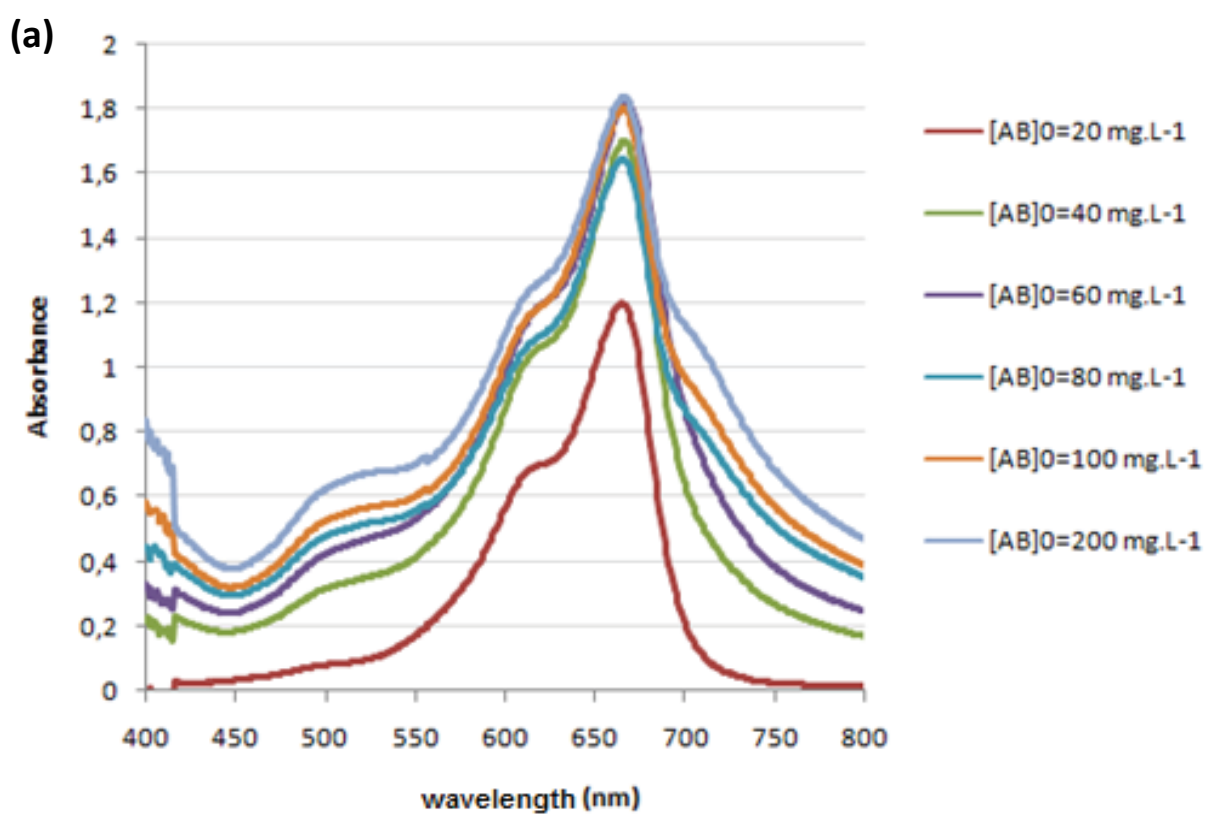

(b)

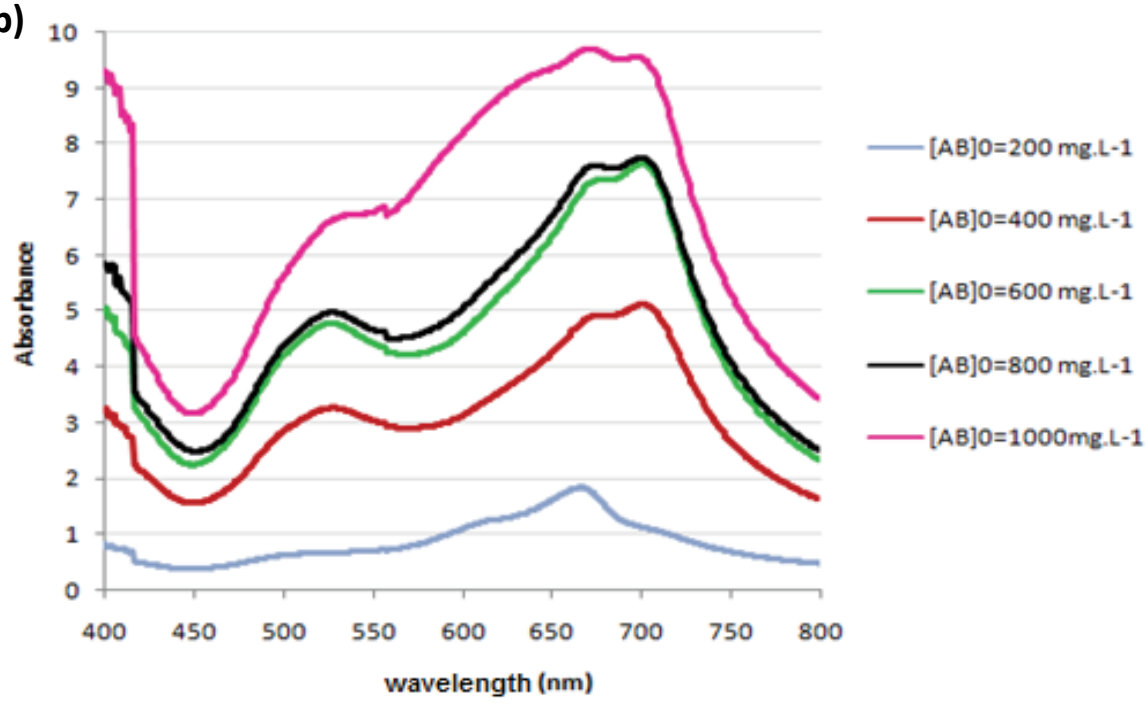

(a) $20 \mathrm{mg} \cdot \mathrm{L}^{-1}<[\mathrm{AB}]_{0}<200 \mathrm{mg} \cdot \mathrm{L}^{-1} ;$ (b) $200 \mathrm{mg} \cdot \mathrm{L}^{-1}<[\mathrm{AB}]_{0}<1000 \mathrm{mg} \cdot \mathrm{L}^{-1}$

Figure 12: Spectral scanning of residual solutions after adsorption of $A B$ onto the extracted cellulose saturated with $B B$ dye. 
Citation: Douissa NB, Dridi-Dhaouadi S, Mhenni MF (2016) Spectrophotometric Investigation of the Interactions between Cationic (C.I. Basic Blue 9) and Anionic (C.I. Acid Blue 25) Dyes in Adsorption onto Extracted Cellulose from Posidonia oceanica. J Textile Sci Eng 6: 240. doi:10.4172/2165-8064.1000240

Page 9 of 9

cellulose and saturated one with $\mathrm{BB}$ dye by taking into account of the cationic dye release, shows quantitatively that adsorption of anionic dye has not enhanced as much as if each dye adsorbed on its own site. However, the shape of the isotherms appears slightly modified because the saturated surface state is different from the raw one.

A previous study [24], which investigated competitive adsorption of anionic and cationic dyes onto multiwalled carbon nanotubes showed that, in binary dye system, synergistic effect was observed. So cationic dye presented favorite adsorption on the sorbent due to hydrophobic effect and $\pi-\pi$ bonds and authors demonstrate that the surface adsorbed cationic dye has a positive charge, which would serve as the sites for electrostatic attraction to negatively charged of the anionic dye. This result is concluded from macroscopic adsorption study, which shows an improvement in the adsorption of anionic dye in binary system compared to single one. However it should be noted that the author did not take into account the dyes mutual interaction in mixture, which leads to drawn wrong conclusions for the adsorption process.

\section{Conclusion}

The extracted cellulose from $P$. oceanica, locally available and low cost material, presented as good alternative adsorbents for Basic blue $9(\mathrm{BB})$ and Acid blue $25(\mathrm{AB})$ removal from aqueous solutions. Equilibrium data agreed well with Langmuir isotherm model with adsorption capacity of 0.955 and $0.370 \mathrm{mmol}^{-1}$ for $\mathrm{BB}$ and $\mathrm{AB}$, respectively. Extracted cellulose before and after dye adsorption was characterized by FTIR spectroscopy and XPS analysis indicating that adsorption of both dyes could be achieved mainly on external fibre surface with different adsorption interactions. It seems that electrostatic and hydrogen bonding involving respectively charged groups and $\mathrm{OH}$ groups takes place in the interaction between dye species and the fibre surface.

On the other hand, the adsorption of $\mathrm{AB}$ dye onto extracted cellulose previously saturated by the $\mathrm{BB}$ was investigated and showed that the determination of residual $\mathrm{AB}$ concentrations cannot be carried directly from the maximum wavelength of the dye, due to its interaction in solution with $\mathrm{BB}$. Indeed, the formation of molecular complex detected at wavelengths 510 and $705 \mathrm{~nm}$ when the anionic $(\mathrm{AB})$ and the cationic $(\mathrm{BB})$ dyes were taken in equimolar proportions, has been revealed and has made it more difficult to determine the binary mixture composition after adsorption. The $\mathrm{AB}$ adsorption isotherm in this case was investigated and showed that the presence of $\mathrm{BB}$ on the surface affects the shape of the adsorption isotherm of the anionic dye but not the adsorbed amounts.

\section{References}

1. Kuo CY, Wu CH, Wu JY (2008) Adsorption of direct dyes from aqueous solutions by carbon nanotubes: determination of equilibrium, kinetics and thermodynamics parameters. J Colloid Interface Sci 327: 308-315.

2. Robinson T, McMullan G, Marchant R, Nigam P (2001) Remediation of dyes in textile effluent: a critical review on current treatment technologies with a proposed alternative. Bioresour Technol 77: 247-255.

3. Barragan BE, Costa C, Carmen Marquez M (2007) Biodegradation of azo dyes by bacteria inoculated on solid media. Dyes Pigments 75: 73-81

4. Zhou Y, Liang Z, Wang Y (2008) Decolorization and COD removal of secondary yeast wastewater effluents by coagulation using aluminum sulfate. Desalination 225: 301-311.

5. Gupta VK, Jain R, Varshney S (2007) Electrochemical removal of the hazardous dye Reactofix Red 3 BFN from industrial effluents. J Colloid Interface Sci 312: 292-296.
6. Hage R, Lienke A (2006) Applications of transition-metal catalysts to textile and wood-pulp bleaching. Angew Chem 45: 206-222

7. Wang S (2008) A Comparative study of Fenton and Fenton-like reaction kinetics in decolourisation of wastewater. Dyes Pigments 76-714-720.

8. El-Qada EN, Allen SJ, Walker GM (2008) Adsorption of basic dyes from aqueous solution onto activated carbons. Chem Eng J 135: 174-184.

9. Hameed BH, Daud FBM (2008) Adsorption studies of basic dye on activated carbon derived from agricultural waste: Hevea brasiliensis seed coat. Chem Eng J 139: 48-55.

10. Aguir C, Khalfaoui M, Laribi N, Mhenni MF (2009) Preparation and characterization of new succinic anhydride grafted Posidonia for the removal of organic and inorganic pollutants. J Hazard Mater 172: 1579-1590.

11. Dridi-Dhaouadi S, Ben Douissa-Lazreg N, Mhenni MF (2011) Removal of lead and Yellow 44 acid dye in single and binary component systems by raw Posidonia oceanica and the cellulose extracted from the raw biomass. Environ Technol 32: 325-340

12. Guezguez I, Dridi-Dhaouadi S, Mhenni MF (2009) Sorption of Yellow 59 on Posidonia oceanica, a nonconventional biosorbent: comparison with activated carbons. Ind Crop Prod 29: 197-204.

13. Ncibi MC, Mahjoub B, Seffen M (2007) Kinetic and equilibrium studies of methylene blue biosorption by Posidonia oceanica (L.) fibres. J Hazard Mater B 139: 280-285.

14. Khiari R, Mhenni M F, Belgacem MN, Mauret E (2010) Chemical composition and pulping of date palm rachis and Posidonia oceanica - A comparison with other wood and non-wood fibre sources. Bioresour Technol 101: 775-780.

15. Aguir C, Mhenni FM (2006) Experimental study on carboxymethylation of cellulose extracted from Posidonia oceanica. J Appl Polym Sci 99: 1808-1816.

16. Boehm HP (1994) Some aspects of the surface chemistry of carbon blacks and other carbons. Carbon 32: 759-769.

17. Akdima O, Chamouna R, Demircia ub, Zaatarb Y, Khouryb A, et al. (2011) Anchored cobalt film as stable supported catalyst for hydrolysis of sodium borohydride for chemical hydrogen storage. International Journal of Hydrogen Energy 36: 14527-14533.

18. Fras L, Johansson LS, Stenius P, Laine J, Stana-Kleinschek K, Ribitsch V (2005) Analysis of the oxidation of cellulose fibres by titration and XPS, Colloids Surf. A: Physicochem Eng Aspects 260: 101-108.

19. Sun RC, Sun XF, Tomkinson J (2004) Hemicelluloses and their derivatives ACS Symposium Series 864: 2-22.

20. Langmuir I (1918) Adsorption of gases on plain surfaces of glass mica platinum J Am Chem Soc 40: 1361-1403.

21. Somani PR, Marimuthu R (2003) Thermal degradation properties of solid polymer electrolyte (poly (vinyl alcohol) +phosphoric acid)/methylene blue composites. Polym Degrad Stabil 79: 77-83.

22. Auta M, Hameed BH (2011) Preparation of waste tea activated carbon using potassium acetate as an activating agent for adsorption of Acid Blue 25 dye. Chem Eng J 171: 502- 509

23. Ben Douissa N, Dridi-Dhaouadi S, Mhenni MF (2014) Study of antagonistic effect in the simultaneous removal of two textile dyes onto cellulose extracted from Posidonia oceanica using derivative spectrophotometric method. J Water Process Eng 2: 1-9

24. Wang Sh, Wei Ng C, Wang W, Li Q, Hao Z (2012) Synergistic and competitive adsorption of organic dyes on multiwalled carbon nanotubes. Chem Eng J 197 34-40. 